\title{
The potential role of contraception in reducing abortion
}

John Bongaarts

Population Council

Charles F. Westoff

Follow this and additional works at: https://knowledgecommons.popcouncil.org/departments_sbsr-pgy

Part of the Demography, Population, and Ecology Commons, Family, Life Course, and Society Commons, and the International Public Health Commons How does access to this work benefit you? Let us know!

\section{Recommended Citation}

Bongaarts, John and Charles F. Westoff. 2000. "The potential role of contraception in reducing abortion," Policy Research Division Working Paper no. 134. New York: Population Council. Version of record: https://doi.org/10.1111/j.1728-4465.2000.00193.x 


\title{
The Potential Role of Contraception in Reducing Abortion
}

\author{
John Bongaarts \\ Charles F. Westoff
}

2000 No. 134 


\title{
The Potential Role of Contraception in Reducing Abortion
}

\author{
John Bongaarts \\ Charles F. Westoff
}

John Bongaarts is Vice President, Policy Research Division, Population Council, New York. Charles F. Westoff is Professor of Demographic Studies and Sociology Emeritus, Princeton University. 


\begin{abstract}
Since the 1960s the proportion of couples practicing contraception has risen rapidly, particularly in the developing world, and the mix of methods is now dominated by modern methods. Despite these trends, the incidence of unintended pregnancy remains high mainly because the number of children desired has declined. Worldwide there are almost as many unintended as intended pregnancies each year (not counting miscarriages, which are excluded in this analysis) and more than half of these unintended pregnancies end in abortion.

This study examines the potential role of further increases in contraceptive prevalence and effectiveness in reducing abortion rates. The model used in this analysis links the abortion rate to its direct determinants, including couples' reproductive preferences, the prevalence and effectiveness of contraceptive practice to implement these preferences, and the probability of an abortion to avoid unintended births when contraception fails or is not used.

An assessment of the tradeoff between contraception and abortion yields estimates of the decline in the total abortion rate that would result from an illustrative increase of 10 percentage points in prevalence. This effect varies among societies, primarily because the tendency to use abortion after an unintended pregnancy varies. For example, in a population with an abortion probability of 0.5 , a 10 percentage point increase in prevalence would avert approximately 0.45 abortions per woman, assuming contraception is 95 percent effective. If all unintended pregnancies were aborted, this effect would be three times larger.

Eliminating all unintended pregnancies and subsequent abortions would require a rise in contraceptive prevalence to the level at which all fecund women who do not wish to become pregnant practice 100 percent effective contraception. A procedure is provided for estimating this "perfect" level of contraceptive prevalence.
\end{abstract}

This material may not be reproduced without written permission from the authors. 
In recent decades, the practice of contraception has changed dramatically in most regions of the world. The proportion of couples using contraception has increased steadily, and the mix of methods is now dominated by modern methods that have become available since the 1960s. This change in reproductive behavior has been most pronounced in the developing world, where contraceptive prevalence has increased from low levels in the 1960s to around 60 percent today, with the large majority of users now relying on modern methods (United Nations 1999). In the developed world, contraception was already widely practiced by the middle of the twentieth century, but it has risen further, and modern methods have been substituted for the traditional ones of the past. Among the key factors driving this change in contraceptive behavior are a decline in the number of children desired, a desire to avoid unintended pregnancies, and the increasing availability of and access to a variety of contraceptive methods.

Couples throughout much of the world are increasingly exerting control over their reproductive lives; despite this trend, however, the incidence of unintended pregnancy remains high. About 133 million births occur in the world annually; out of this total one in four (33 million) is estimated to be unintended - either mistimed or never wanted (Alan Guttmacher Institute 1999). In addition there are an estimated 46 million induced abortions, bringing the total number of unintended pregnancies to about 79 million per year. In other words, there are almost as many unintended as intended pregnancies each year (not counting miscarriages, which are excluded in this analysis), and more than half of these unintended pregnancies end in abortion. Clearly, the regulation of fertility is far from perfect, and the use of abortion is widespread.

These global estimates conceal wide variation among populations. In general, developing regions with relatively high birth rates (Africa, Latin America, and South Asia) have higher rates of reported unintended pregnancy and abortion than developed regions with low birth rates (North America, East Asia, Western Europe, Japan, and Oceania). However, the reverse is true for the proportion of all pregnancies reported as unintended. More than half of all pregnancies (56 percent) are unintended in the developed world, compared to 42 percent in the developing world. The proportion of all pregnancies ending in abortion is also higher in the more developed than in the less developed world (41 percent vs. 23 percent).

This study describes and analyzes a model linking the abortion rate to its direct determinants. The main focus of the analysis is the potential role of increases in levels of contraceptive prevalence and effectiveness in reducing abortion rates. 


\section{The Determinants of Unintended PREgnanCy}

\section{AND ABORTION RATES}

The direct determinants of pregnancy outcomes are the desired number and spacing of births, the prevalence and effectiveness of contraceptive practice to implement these preferences, and the probability of an abortion to avoid unintended births when contraception fails or is not used.

\section{Fertility Preferences}

The number of children desired is one of the key factors affecting a population's level of unintended pregnancy. In societies where large families are desired, the potential unintended pregnancy rate tends to be low (Bongaarts 1997). As societies move through the fertility transition, the desired number of children declines along with the number of years needed to bear intended children. This implies that the number of years during which women are potentially at risk of an unintended pregnancy increases commensurately. In post-transitional populations with small-family norms of around two children, the number of unintended pregnancies per woman can be large unless women are protected from this risk by practicing effective contraception. Estimates of the desired number of children range from approximately five in sub-Saharan Africa to two in the Western world.

Spacing preferences also influence the potential unintended pregnancy rate. Women who prefer longer birth intervals are at greater risk of experiencing unintended pregnancies. This is a key consideration in the analysis of abortion rates, because mistimed as well as unwanted pregnancies are potentially subject to interruption.

\section{Prevalence and Effectiveness of Contraception}

The actual rate of unintended pregnancy depends not only on the potential rate, but also on the extent to which women practice contraception and its effectiveness. No unintended pregnancies would occur if all women who wish to avoid pregnancy were to use perfect contraception. Because not all such women practice contraception, and methods are less than 100 percent effective, the perfect contraceptive society (Bumpass and 
Figure 1 Trends in the total abortion rate and in contraceptive prevalence, Korea 1960-96

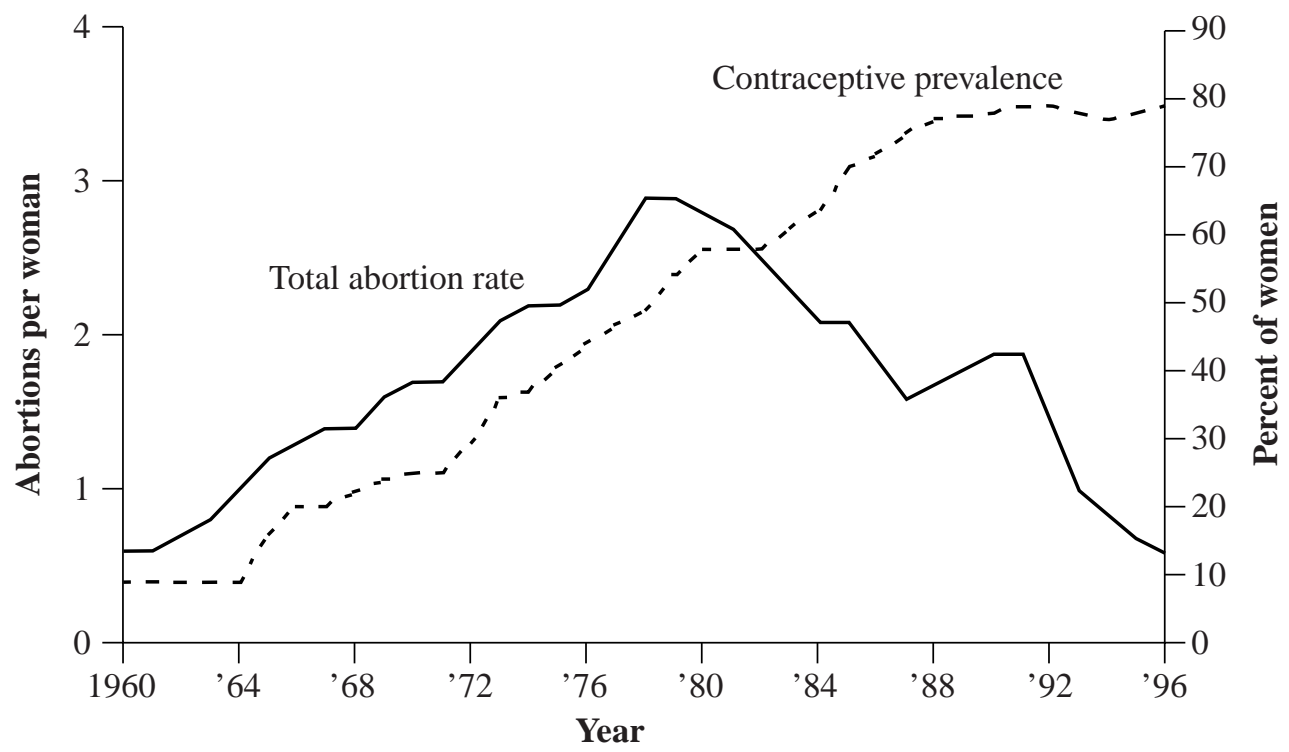

Sources: Alan Guttmacher Institute 1999; Ross et al. 1999; Tietze 1979; United Nations 1999.

Westoff 1970) is only an ideal. Contraceptive prevalence varies around the world from less than 10 percent of women of reproductive age in some sub-Saharan countries to around 75 percent in many developed countries.

\section{Probability of Abortion of Unintended Pregnancies}

The actual abortion rate depends both on the rate of unintended pregnancy and on the probability that such pregnancies are terminated by abortion. The proportion of unintended pregnancies that end in abortion is estimated at 58 percent worldwide, but there are large variations among regions. This proportion is higher in the developed world (73 percent) than in the developing world (54 percent), ranging from a high of 91 percent in Eastern Europe to a low of 41 percent in Africa (Alan Guttmacher Institute 1999).

In general, abortion rates are highest in societies where small families are desired, because of the increase in the risk of unintended pregnancy; in societies where 
low contraceptive prevalence or ineffective methods are combined with low-fertility norms; and in societies with a high propensity to rely on induced abortion. Relatively low abortion rates are found in societies with high desired fertility or high levels of effective contraception, or with a low propensity to use abortion. Populations passing through the fertility transition can reveal historically the operation of these different forces at different times. In Korea, for example, the abortion rate rose from around 0.5 abortions per woman in 1960 to nearly 3.0 per woman in the late 1970s (see Figure 1) as the small-family norm spread and before contraception had become widely available and acceptable. As contraceptive prevalence increased to about 50 percent, the abortion rate reversed its upward trend and declined back to its initial level by 1996. During this entire period, the total fertility rate declined from around 6 to 1.7 births per woman. Similar crossovers in rates of abortion and contraceptive prevalence have been observed in parts of Eastern Europe such as Hungary and, more recently, in some of the republics of the former Soviet Union such as Kazakstan (Westoff et al. 1998).

\section{ANALYTIC FrameWORK}

In analyzing the causes of variation in abortion rates, we will rely on an analytic model that relates the total abortion rate (TAR) and the total fertility rate (TFR) to their various direct determinants. ${ }^{1}$ The following description of the model begins with an examination of a population with no contraception and no induced abortion and moves on to increasingly more realistic versions of the model.

\section{No Fertility Regulation}

Let $\mathrm{Y}_{\mathrm{R}}$ (reproductive years) be the average number of years in which women are both able to bear children (i.e., fecund) and exposed to the risk of childbearing by being in a marital or consensual union. For several reasons $Y_{R}$ is less than the 35 potential childbearing years between the ages of 15 and 50. Most women delay entry into a permanent sexual union for a few years after menarche, and some women experience marital disruption. In addition, the onset of permanent infecundity usually occurs a few years before menopause. As a consequence, $\mathrm{Y}_{\mathrm{R}}$ typically averages $20-25$ years in contemporary developing countries. 
In the absence of deliberate efforts to limit fertility, the number of births that occur during $\mathrm{Y}_{\mathrm{R}}$ depends on the average duration of a birth interval. A typical birth interval is much longer than the nine months of a full-term pregnancy because pregnancy is preceded by a waiting time to conception (which may include miscarriages) and is followed by a period of postpartum infecundability because of the ovulationinhibiting effect of breastfeeding or temporary abstinence from sexual relations. We will use the term "birth interval" in a somewhat unconventional way as the sum of the waiting time to conception (including time for miscarriages), nine months for the pregnancy ending in a live birth, and the interval of postpartum infecundability. This definition allows the measurement of a birth interval even when a woman has only one birth. In effect, the birth interval so defined equals the amount of reproductive time allocated to a birth. If the average birth interval duration equals $I_{B}$, then the average number of births per woman at the end of the reproductive years is simply estimated as TFR $=\mathrm{Y}_{\mathrm{R}} / \mathrm{I}_{\mathrm{B}}$. The pattern of reproduction depicted in the first bar of Figure 2 assumes $Y_{R}=20$ years and $I_{B}=2.5$ years, yielding a TFR of eight births per woman. The reproductive model presented here assumes that the average birth interval does not change with age. This is a reasonable approximation of reality, as shown by Bongaarts and Potter (1983). ${ }^{2}$

\section{Contraception, but No Induced Abortion}

Let $u$ be the proportion of $\mathrm{Y}_{\mathrm{R}}$ during which contraception is used ( $u$ represents the lifecycle counterpart of the more familiar contraceptive prevalence rate). ${ }^{3}$ If contraceptive practice is perfect, then only $\mathrm{Y}_{\mathrm{R}}(1-u)$ years are available for actual childbearing, so that TFR $=\mathrm{Y}_{\mathrm{R}}(1-u) / \mathrm{I}_{\mathrm{B}}$. The second bar in Figure 2 illustrates this pattern with $u=0.75$, implying that contraception is used for three-quarters of the reproductive years. $Y_{R}$ is again assumed to be 20 and $I_{B}=2.5$, yielding a TFR of two births. In this example with contraceptive prevalence at 75 percent, reproduction is confined to five years $\left(\mathrm{Y}_{\mathrm{R}}(1-u)=5\right)$, which implies two births by the end of the reproductive years with an average birth interval of 2.5 years. If contraception is not perfect, then $e^{*} u$ is substituted for $u$ in this equation, where $e$ equals the average effectiveness of contraception. $^{4}$ 
Figure 2 Hypothetical patterns of reproduction

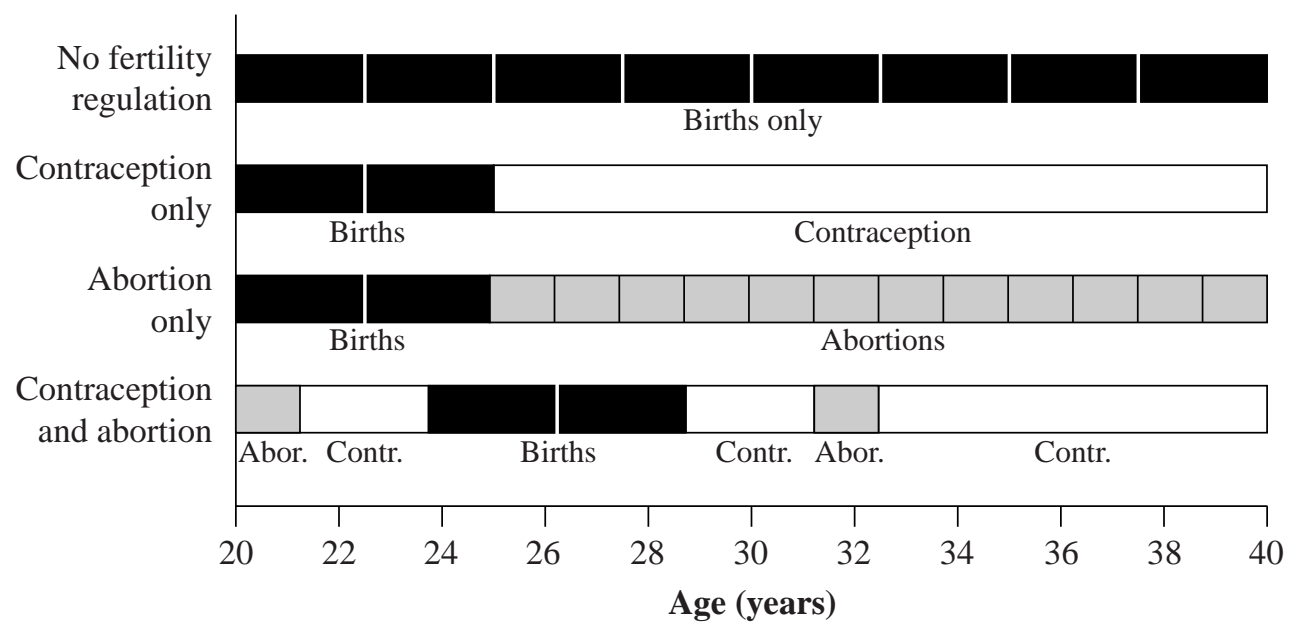

\section{Induced Abortion, but No Contraception}

The reproductive time allocated for an induced abortion $\left(\mathrm{I}_{\mathrm{A}}\right)$ is shorter than that allocated for a birth $\left(\mathrm{I}_{\mathrm{B}}\right)$. Both $\mathrm{I}_{\mathrm{B}}$ and $\mathrm{I}_{\mathrm{A}}$ are defined as the sum of waiting time to conception (including miscarriages), pregnancy (ending in a birth or abortion), and the postpregnancy period of insusceptibility. The pregnancy interval preceding an induced abortion is typically less than three months, in contrast to nine months for a full-term pregnancy, and there is no lactational amenorrhea following an abortion. Values of $\mathrm{I}_{\mathrm{A}}$ are typically a little over one year (Bongaarts and Potter 1983). In the absence of contraception, reproductive years, $Y_{R}$, are allocated either to births (for a total of TFR $* \mathrm{I}_{\mathrm{B}}$ years) or to induced abortions (for a total of $\mathrm{TAR} * \mathrm{I}_{\mathrm{A}}$ years), so that $\mathrm{Y}_{\mathrm{R}}=\mathrm{TFR} * \mathrm{I}_{\mathrm{B}}+\mathrm{TAR} * \mathrm{I}_{\mathrm{A}}$. The third bar in Figure 2 illustrates such a pattern of reproduction assuming $\mathrm{Y}_{\mathrm{R}}=20, \mathrm{I}_{\mathrm{B}}=2.5, \mathrm{I}_{\mathrm{A}}=1.25$, and TFR $=2$. In this example with no contraceptive use, 12 abortions are needed to restrict fertility to two births per woman.

\section{Induced Abortion and Contraception}

Most populations rely on both contraception and induced abortion to regulate fertility. The reproductive years are then allocated to contraceptive use $\left(\mathrm{Y}_{\mathrm{R}} * e^{*} u\right)$, to births $\left(\mathrm{TFR} * \mathrm{I}_{\mathrm{B}}\right.$ ), and to abortions $\left(\mathrm{TAR} * \mathrm{I}_{\mathrm{A}}\right)$, giving the following general equation for $Y_{R}$, which equals the sum of its three components: 


$$
\mathrm{Y}_{\mathrm{R}}=\mathrm{Y}_{\mathrm{R}} * e * u+\mathrm{TFR} * \mathrm{I}_{\mathrm{B}}+\mathrm{TAR} * \mathrm{I}_{\mathrm{A}}
$$

Rearranging the equation results in ${ }^{5}$ :

$$
\mathrm{TAR}=\mathrm{Y}_{\mathrm{R}}(1-e * u) / \mathrm{I}_{\mathrm{A}}-\mathrm{TFR} * \mathrm{I}_{\mathrm{B}} / \mathrm{I}_{\mathrm{A}}
$$

This equation is valid regardless of the sequence in which segments of contraceptive use, births, and induced abortions occur during the reproductive years, and it applies equally to the regulation of fertility for the spacing and limiting of births. The last bar in Figure 2 illustrates such a situation, using the previous values for TFR, $I_{B}, I_{A}$, and $Y_{R}$ and assuming $u=0.625$ and $e=1$, resulting in a TAR of 2 . In this example, fertility is restricted to two births per woman by a combination of abortion and contraception.

To complete the model, we introduce the abortion probability, $p$, which is defined as the proportion of unintended pregnancies (abortions plus unintended births) aborted:

$$
p=\mathrm{TAR} /(\mathrm{TAR}+\mathrm{UITFR})
$$

where UITFR equals the part of the total fertility rate that is unintended (i.e., either mistimed or unwanted). TFR is the sum of its intended and unintended parts (i.e., TFR = UITFR + ITFR).

Equation (2) can now be rewritten as:

$$
\mathrm{TAR}=p *\left(\mathrm{Y}_{\mathrm{R}} *(1-e * u)-\mathrm{ITFR} * \mathrm{I}_{\mathrm{B}}\right) /\left(p * \mathrm{I}_{\mathrm{A}}+(1-p) * \mathrm{I}_{\mathrm{B}}\right)
$$

This equation relates TAR to the three key determinants discussed in the preceding section: fertility preferences as measured by the intended total fertility rate (ITFR); the prevalence and effectiveness of contraception, $u$ and $e$; and the abortion probability as measured by $p$. TAR is also a function of three other factors (i.e., $\mathrm{Y}_{\mathrm{R}}, \mathrm{I}_{\mathrm{B}}$, and $\mathrm{I}_{\mathrm{A}}$ ).

Equations (2) and (4) summarize the model for the determinants of induced abortion used in the following sections of this study. These equations have been presented in a general form so that they can be applied either to the reproductive patterns of cohorts of women or in summarizing reproductive patterns for recent time periods (see Appendix for further details).

\section{Potential Uses of the Analytic Framework}

The preceding model of the relationship between TAR and its determinants can be used in a variety of ways. Given the lack of reliable statistics on abortion, it is tempt- 
ing to apply these equations to estimate the TAR in populations where abortion rates are not available from other sources. This would indeed be possible if highly accurate estimates of the various factors on the right-hand side of these equations were available. In practice, however, this is not likely to yield satisfactory results, because accurate estimates of some of the determinants are difficult to obtain from survey data or other sources, and because the estimates of TAR provided by our model are highly sensitive to small errors in these estimates. For example, in a population in which the measured TFR contains an error of 0.2 births (not unusual in developing countries), the TAR calculated with equation (2) would have an error of 0.4 (assuming $\mathrm{I}_{B} / \mathrm{I}_{A}=2$ ). If the actual TAR in this population is 0.5 then this small error in the TFR leads to a very large relative error in the TAR, which would be estimated as either 0.1 or 0.9 depending on whether the TFR error is positive or negative. Measurement errors in the other determinants make the potential error in the estimated TAR even larger. We therefore do not encourage the use of these equations for the empirical estimation of abortion rates in populations where abortion statistics are lacking, because it is unlikely that the various determinants of abortion can be estimated with sufficient accuracy to yield reasonable results.

In this study we apply the model for a different purpose. We assume that levels of TAR and its determinants can be estimated from surveys or other sources, and we seek to quantify the effects on TAR of changes in the various determinants. Specifically, we estimate how reductions in abortion rates can be achieved by increases in contraceptive prevalence and effectiveness - an issue of clear policy importance. It would be possible to design an experiment to measure the impact of changes in contraceptive behavior on abortion, but that approach would be expensive and time-consuming. We therefore rely on an analytic approach to provide general insights into this relationship.

\section{TRADEOFF BETWEEN ABorTION AND CONTRACEPTION}

To simplify the analysis of this tradeoff, we initially assume fixed values for several of the factors affecting the total abortion rate, as was done in Figure 2 (i.e., $e=1$, $Y_{R}=20, I_{B}=2.5$, and $\left.I_{A}=1.25\right)$. With these assumptions TAR is affected only by variations in TFR and $u$, according to equation (2). ${ }^{6}$ Figure 3 plots the TAR as a function of 
Figure 3 Relationship between the total abortion rate and prevalence of contraceptive use, according to various levels of the total fertility rate

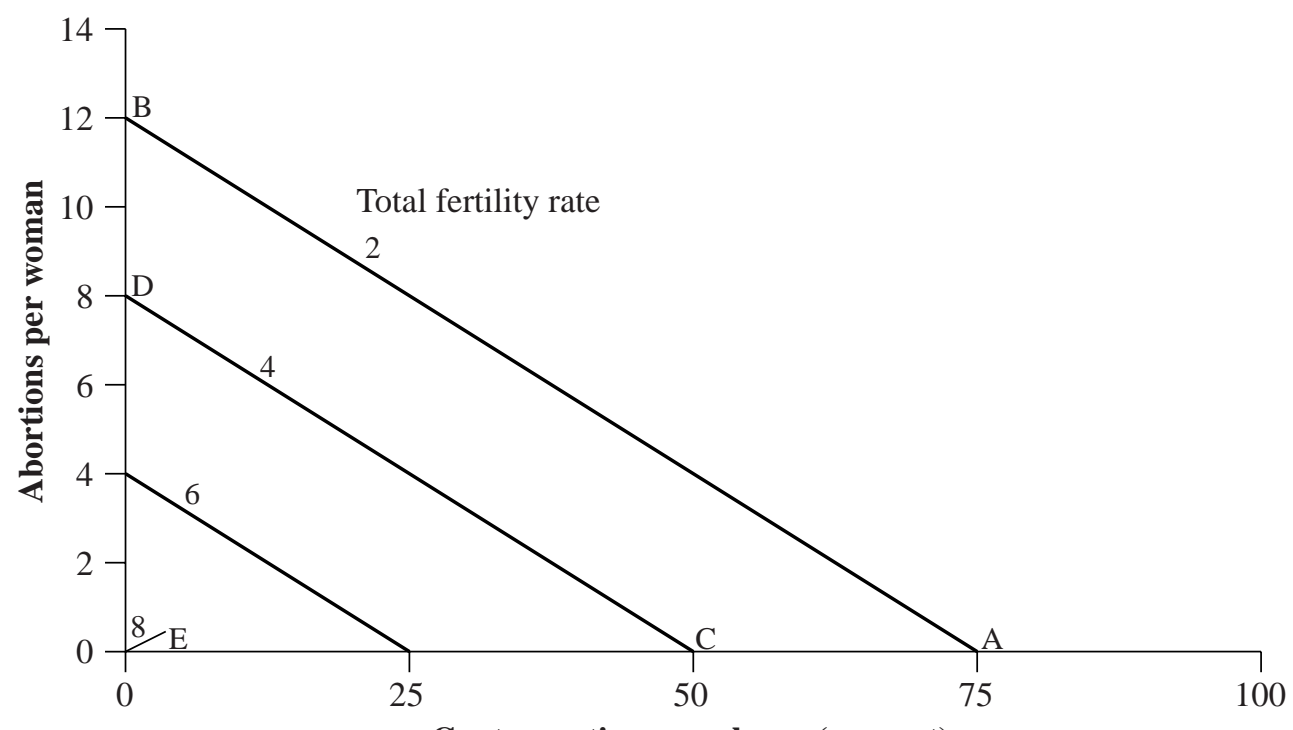

Contraceptive prevalence (percent)

contraceptive prevalence for different levels of fertility. A population with a TFR of 2 is somewhere on line $\mathrm{AB}$. In the absence of contraception this population will be at point $\mathrm{B}$, with a TAR of 12 (this corresponds to the pattern presented in the third bar in Figure 2); at the other extreme, if contraceptive prevalence reaches 75 percent, then the abortion rate would be zero (point A in Figure 3, and the second bar in Figure 2).

As expected, the higher the level of fertility, the lower the abortion rate and the level of contraceptive prevalence. ${ }^{7}$ For example, with a TFR of 4 , a contraceptive prevalence rate of 50 percent among fecund exposed women would suffice to avert all abortions (point $\mathrm{C}$ in Figure 3), but without contraception the abortion rate would be 8 (point D). In the absence of both abortion and contraception, the TFR would be 8 (point $\mathrm{E}$ and the first bar in Figure 2).

In this hypothetical illustration, there is a clear tradeoff between abortion and contraception. With a TFR of 2, a 75 percent prevalence has the same fertility-reducing effect as 12 abortions, while with a TFR of 4 , a 50 percent prevalence is equivalent to 
eight abortions. These results imply that a rise of 10 percentage points in contraceptive prevalence averts 1.6 induced abortions per woman at any given level of fertility. An assumption made in obtaining this estimate is that fertility remains constant when prevalence is changed. In reality, any rise in contraceptive prevalence will avert not only abortions but also unintended births. As a consequence, an increase in prevalence of 10 percentage points usually averts less than 1.6 induced abortions per woman. The actual number of averted abortions depends on a number of factors, which we will discuss next, beginning with the effect of variation in the abortion probability.

The role of this probability, $p$, in the tradeoff between contraceptive prevalence and abortion rates can be examined with equation (4). According to this equation TAR is a function of $p$, $u$, and ITFR (again assuming fixed values for $e, \mathrm{Y}_{\mathrm{R}}, \mathrm{I}_{\mathrm{B}}$, and $\mathrm{I}_{\mathrm{A}}$ ). ${ }^{8}$ Because it is difficult to plot the relationships between all of these variables in one figure, we simplify further and examine only populations with an intended total fertility rate of two births per woman.

Figure 4 plots estimates of TAR by $u$ for values of $p$ ranging from 0 to 1 when ITFR $=2$. The abortion rate equals 0 if $u=75$ percent because in that case all women who do not wish to become pregnant practice perfect contraception so that there are no unintended pregnancies and the TFR $=$ ITFR $=2$ (point A in Figures 3 and 4). Unintended pregnancies do occur if the prevalence drops below 75 percent, and the TAR then depends on the abortion probability and on the extent to which $u$ deviates from the "perfect" level of 75 percent. For example, a decline in $u$ from 75 percent to 50 percent would result in a TAR of 0 if the abortion probability is 0 (point $\mathrm{C}$ ), but the TAR would be 1.33 with $p=0.5$ (point $\mathrm{E}$ ) and 4 with $p=1$ (point F). ${ }^{9}$ When $p$ is less than 1.0 (i.e., when not all unintended pregnancies are aborted), unwanted and/or mistimed births occur. For example, with $u=50$ percent and $p=0$ (point $\mathrm{C}$ in Figures 3 and 4), women average two unintended births each, which together with two intended births yields a TFR of 4 (and a TAR of 0 ).

To quantify the tradeoff between contraceptive prevalence and abortion, we introduce a new variable $t$, which equals the reduction in the TAR resulting from an increase of 10 percentage points in contraceptive prevalence. It is clear from Figure 4 that $t$ varies with the probability of an abortion. For example, with $p=1$ a change in $u$ would 
Figure 4 Relationship between the total abortion rate and prevalence of contraceptive use, according to various levels of the abortion probability, assuming ITFR $=2$

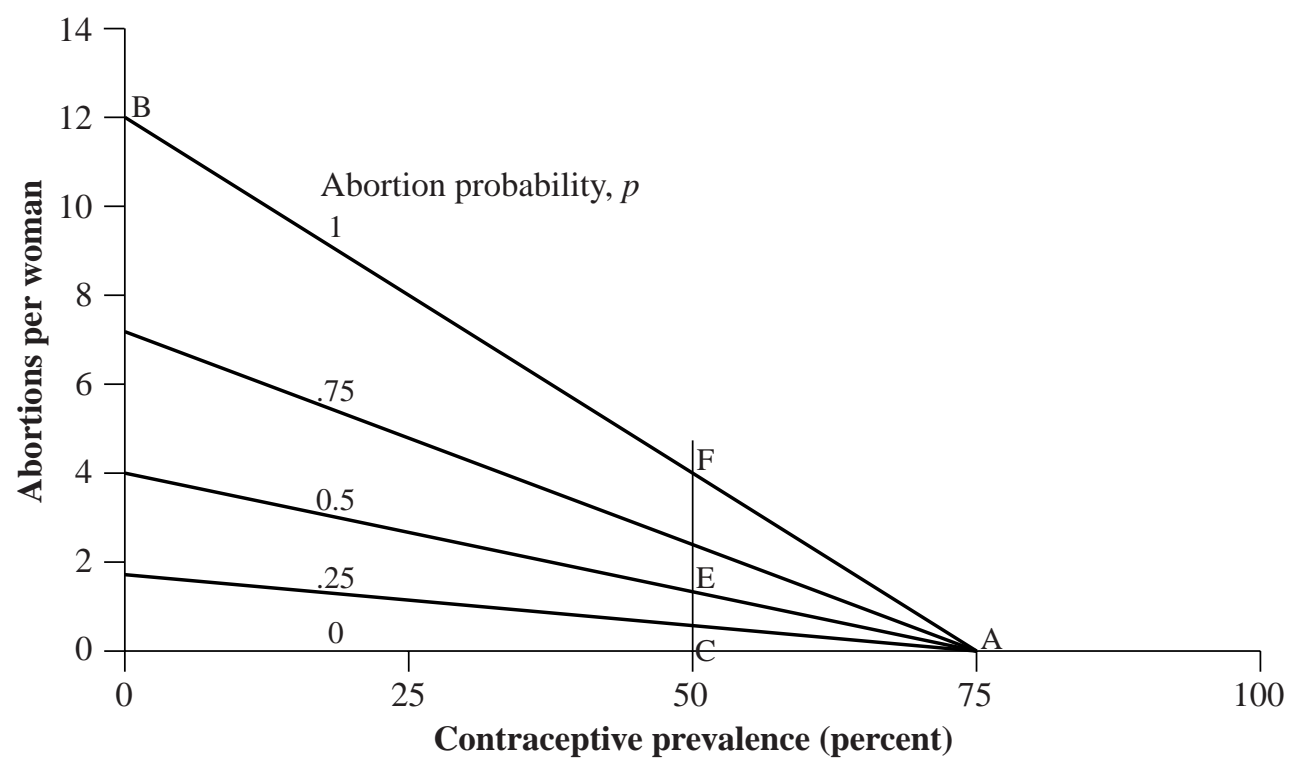

move the population along line $\mathrm{AB}$ where $t=1.6$, but with lower values of $p$ fewer abortions are averted for the same increase in $u$. Illustrative values of $t$ and $p$ are as follows ${ }^{10}$ :

Abortions averted by an increase of

Abortion probability

$$
p=
$$

1.0

0.75

0.5

0.25 10 percentage points in contraceptive prevalence $t=$

1.6

1.0

0.5

0.2

These results indicate a strong direct relationship between the probability of abortion and the effect of a change in prevalence on TAR. The higher the abortion probability the greater the reduction in the TAR for a given increase in prevalence.

We examine next how abortion rates are affected by changes in contraceptive effectiveness. Figure 5 plots estimates of TAR by contraceptive prevalence for different values of the abortion probability ( $p=0,0.5$, and 1) and for three effectiveness levels 
Figure 5 Relationship between the total abortion rate and prevalence of contraception, according to various levels of abortion probability and contraceptive effectiveness, assuming ITFR $=2$

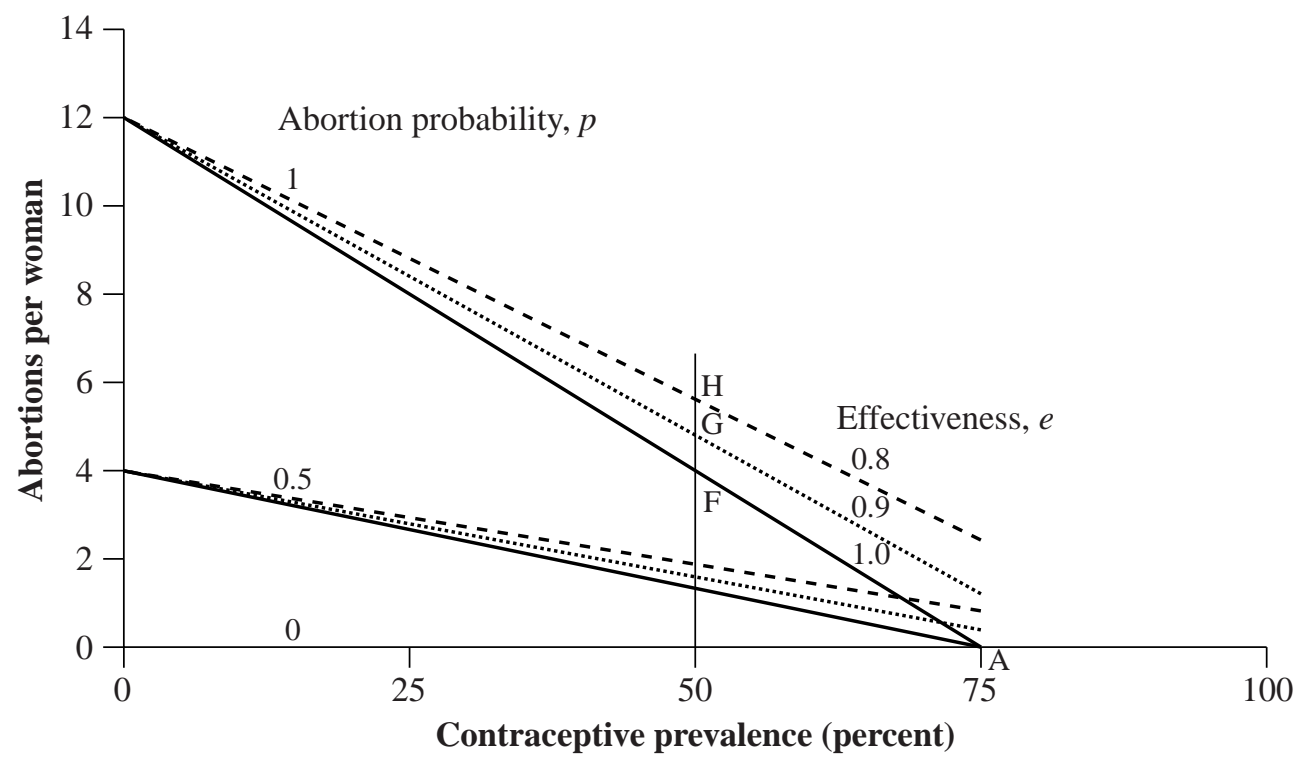

( $e=1$ [as in Figure 4], 0.9, and 0.8), with the other determinants the same as in Figure 4. The impact of variation in effectiveness is small at low prevalence levels, but it becomes substantial at high prevalence rates. For example, in a population with a prevalence of 50 percent, the TAR would be 4.0 with 100 percent effectiveness (point F, as in Figure 4). However, assuming an abortion probability of 1.0, the TAR would rise to 4.8 with $e=0.9$ (point $\mathrm{G}$ ) and to 5.6 with $e=0.8$ (point $\mathrm{H}$ ). Less than perfect contraceptive practice therefore can be an important cause of unintended pregnancies and abortion. In addition, contraceptive failure lowers the impact on TAR of a given increase in prevalence. If effectiveness is less than 100 percent, the preceding estimates for $t$ should be multiplied by $e$ to obtain the number of abortions averted by a 10 percentage point increase in prevalence.

Up to this point, the analysis has focused on the effects of contraceptive prevalence and effectiveness and the abortion probability on TAR, while ignoring effects of 
Table 1 Model estimates of the total abortion rate as a function of its various determinants, assuming $p=0.5$ and $e=0.9$

Contraceptive prevalence $(u)(\%)$

\begin{tabular}{llll}
\hline 0 & 25 & 50 & 75 \\
\hline
\end{tabular}

Intentional total fertility rate (ITFR)

(births per woman)

2

3

4

5

Average duration of reproductive years $\left(\mathrm{Y}_{\mathrm{R}}\right)$ (years)

17.5

20

25

Average duration of birth interval $\left(\mathrm{I}_{\mathrm{B}}\right)$ (years)

2

2.5

3

Average duration of abortion interval $\left(\mathrm{I}_{\mathrm{A}}\right)$ (years)

1

1.25

1.5
4.0

3.3

2.7

2.0
2.8

2.1

1.5

0.8
3.3

4.0

5.3

4.9

4.0

3.3

4.3

4.0

3.8
2.3

2.8

3.8

1.6

0.4

0.9

0.3

0.8


Figure 6 Relationship between the total abortion rate and contraceptive prevalence for 34 developed countries

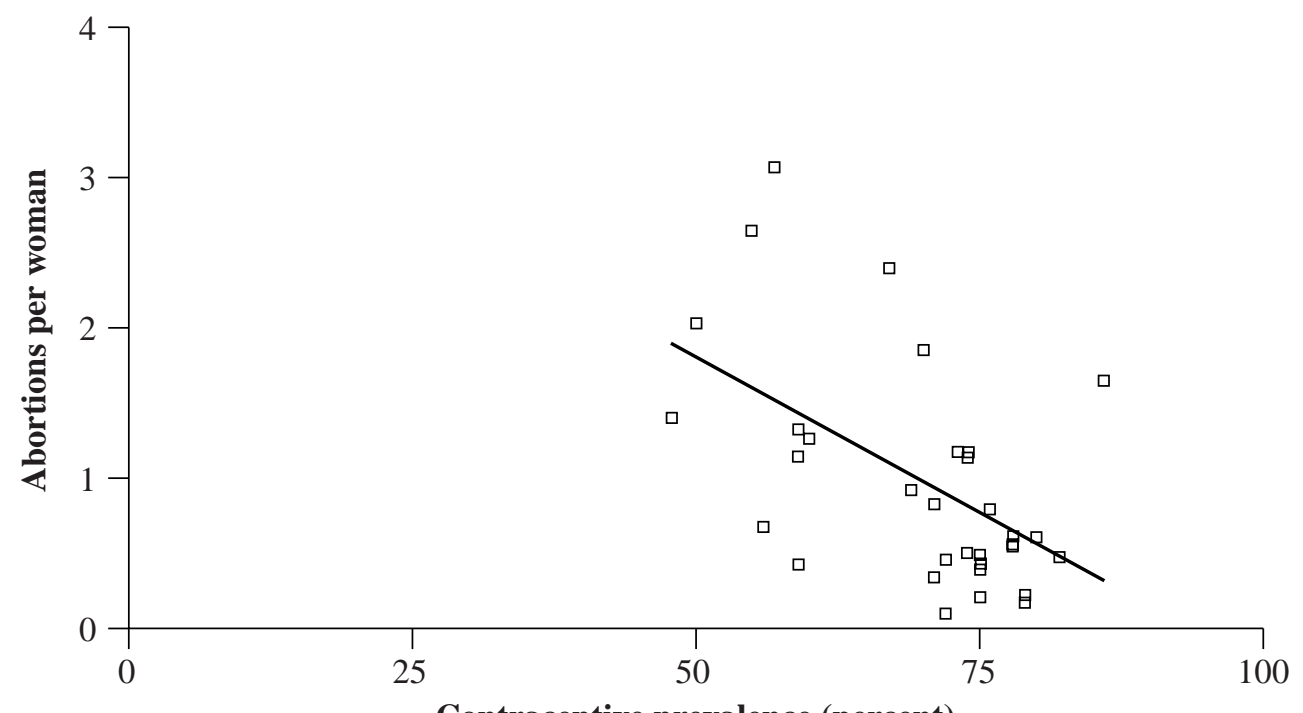

Sources: Alan Guttmacher Institute 1999; United Nations 1999.

relationship between ITFR and TAR at any given level of prevalence. This finding is consistent with the earlier discussion of the role of fertility preferences and the patterns plotted in Figure 3. Second, reductions in the duration of the exposed fecund reproductive years $\left(\mathrm{Y}_{\mathrm{R}}\right)$ have a direct negative impact on TAR. This is as expected because with fewer years of exposure to the risk of unintended pregnancy, the number of abortions per woman should decline, all else equal. Finally, the TAR is less sensitive to variations in $I_{B}$ and $I_{A}$ than to variations in $Y_{R}$ and ITFR. Nevertheless, the longer the average birth and abortion intervals, the lower the abortion rate.

The preceding examination of the tradeoff between contraception and abortion is based on applications of a theoretical model. Direct testing of the validity of the model in actual populations is difficult owing to the lack of accurate data on abortion rates and their determinants in most societies. However, for a number of developed countries fairly reliable estimates of abortion rates are available (Alan Guttmacher Institute 1999), 
and these data can be used for a simple comparison. Figure 6 plots estimates of the total abortion rate as a function of the conventional contraceptive prevalence rate for 34 developed countries. These countries have TFRs of nearly two births per woman; one would expect, therefore, an inverse relationship as observed in Figure 5. The data plotted in Figure 6 indeed show such an inverse relationship, but there is considerable variation around the predicted pattern. This is most likely due to variation in other determinants of abortion $\left(\mathrm{Y}_{\mathrm{R}}, e, \mathrm{I}_{\mathrm{B}}, \mathrm{I}_{\mathrm{A}}, \mathrm{TFR}\right)$ that is not eliminated in Figure 5 because comparable estimates for these factors are not available. The slope of the (least squares) linear regression line in this figure implies that a 10 percentage point increase in prevalence is associated with an estimated average reduction of 0.41 in the total abortion rate in this group of countries.

\section{Toward a Perfect Contraceptive Population}

We conclude by estimating the changes in contraceptive behavior required to remove all abortions. To avert all unintended pregnancies, contraceptive prevalence and effectiveness have to rise until the ideal situation is reached in which all women who do not wish to become pregnant practice completely effective contraception.

In such a perfect contraceptive population no abortions occur, ${ }^{11}$ effectiveness equals 100 percent, and no unwanted or unintended births occur, so that TFR is reduced to its wanted level (TFR = WTFR). The wanted total fertility rate (WTFR) is defined as the sum of mistimed and intended births, but with perfect contraception no mistimed births occur and therefore ITFR $=$ WTFR..$^{12}$

Let $u_{\mathrm{p}}$ be the contraceptive prevalence under such perfect conditions. $u_{\mathrm{p}}$ is estimated by substituting TAR $=0, e=1$, and TFR $=$ WTFR in equation (2), resulting in

$$
u_{\mathrm{p}}=1-\mathrm{WTFR} * \mathrm{I}_{\mathrm{B}} / \mathrm{Y}_{\mathrm{R}}
$$

This estimate of $u_{\mathrm{p}}$ assumes that completely effective contraception is used throughout the exposed fecund reproductive period, except during the years needed to have wanted births (a total of WTFR $* \mathrm{I}_{\mathrm{B}}$ years) and $u_{\mathrm{p}}$ is therefore independent of TAR, $p$, and $\mathrm{I}_{\mathrm{A}}$.

To illustrate, we examine a hypothetical population in which $\operatorname{TFR}=4, \operatorname{ITFR}=2$, $\operatorname{TAR}=0$, and $u=50$ percent (other factors the same as in Figure 4). This population is 
represented by point $\mathrm{C}$ in Figure 4. The elimination of all unintended births would move this population from $\mathrm{C}$ to $\mathrm{A}$, where $\mathrm{TFR}=\mathrm{ITFR}=\mathrm{WTFR}=2$ and $\mathrm{TAR}=0$. The contraceptive prevalence at point $\mathrm{A}\left(u_{\mathrm{p}}\right)$ equals 75 percent, an increase of 25 percentage points. In this case, a rise of 25 percentage points is required to avert all unintended pregnancies. The increase in prevalence from $u$ to $u_{\mathrm{p}}$ reflects a prevalence gap that is often referred to as the unmet need for contraception. Because this gap as measured here is not directly comparable to conventional unmet need measures (which are not age-standardized), the term "gap" will be used in the discussion below.

It should be noted that mistimed but wanted births do not affect $u_{\mathrm{p}}$. This is because in a perfect contraceptive society these births still occur, but they have been moved to a somewhat higher age (typically by $2-3$ years). This move does not affect TFR except during the temporary period when these births are being delayed to achieve their desired timing. During this brief transition period, contraceptive prevalence can be higher than $u_{\mathrm{p}}$ and fertility can be lower than WTFR. Further discussion of the fertility effects of changes in the timing of childbearing can be found in Bongaarts and Feeney (1998). $u_{\mathrm{p}}$ is best interpreted as the contraceptive prevalence that would be observed at present if all women had practiced perfect contraception in the recent past.

The level of $u_{\mathrm{p}}$ in a population can be calculated with equation (5), provided that estimates of WTFR, $Y_{R}$, and $I_{B}$ are available. Table 2 presents these estimates, as well as estimates of $u$ and $u_{\mathrm{p}}$ for Kazakstan. This population was chosen because a direct estimate of the total abortion rate is available from a recent DHS survey, which is not the case in most countries with DHS surveys (National Institute of Nutrition [Kazakstan] and Macro International 1996). The procedures used to estimate the variables in Table 2 are described in the Appendix. The increase in contraceptive use $\left(u_{\mathrm{p}}-u\right)$ that would be required to achieve perfect contraception, given the observed levels of WTFR, $I_{B}$, and $\mathrm{Y}_{\mathrm{R}}$, is 9 percentage points (i.e., 74 percent-65 percent) in this country.

Achieving a perfect contraceptive population requires not only an increase in prevalence to $u_{\mathrm{p}}$ but also an increase in effectiveness to 100 percent. Clearly, unintended pregnancies will continue to occur as long as contraception is less than perfect, regardless of the degree to which prevalence is raised. The effectiveness of contraception in Kazakstan is estimated at 97 percent. The elimination of all unintended pregnancies and 
Table 2 Estimates of the total fertility rate, total abortion rate, and determinants of abortion for Kazakstan, 1995

Total fertility rate (TFR)

Total abortion rate (TAR)

Wanted total fertility rate (WTFR)

Intended total fertility rate (ITFR)

Abortion probability $(p)$

Reproductive years $\left(\mathrm{Y}_{\mathrm{R}}\right)$

Average birth interval $\left(\mathrm{I}_{\mathrm{B}}\right)$

Contraceptive prevalence $(u)$

Perfective contraceptive prevalence $\left(u_{\mathrm{p}}\right)$

Contraceptive effectiveness $(e)$

0.97

Sources: DHS data file and Appendix.

subsequent abortions in Kazakstan therefore requires an increase in prevalence from 65 percent to 74 percent and in effectiveness from 97 percent to 100 percent. The relatively larger gap for prevalence than for effectiveness indicates that the former is a more important cause of abortion than the latter. ${ }^{13}$

\section{CONCLUSION}

This analysis of the direct determinants of abortion rates identified seven factors that can contribute to variations in these rates among countries. As expected, the total abortion rate is inversely related to the prevalence and effectiveness of contraception and to fertility preferences, but it is directly related to the probability of an abortion following an unintended pregnancy, as well as to the average duration of the fecund exposed reproductive years. In addition, longer birth and abortion intervals are associated with fewer abortions by the end of the reproductive years. Applications of a model linking TAR to its determinants found TAR to be highly sensitive to variations in the prevalence of contraception, the abortion probability, and the intended total fertility rate.

The incidence of abortion can be reduced by raising contraceptive prevalence and/or effectiveness. An examination of the tradeoff between contraception and abortion yielded estimates of the decline in TAR that would result from an increase of 10 
percentage points in prevalence. This effect varies among societies, primarily because the tendency to use abortion after an unintended pregnancy varies. For example, in a population with an abortion probability of 0.5 , a 10 percentage point increase in prevalence would avert 0.45 abortions per woman, assuming contraception is 95 percent effective (and standard values for the other determinants). With an abortion probability of 1 , this effect would be three times larger.

Eliminating all unintended pregnancies and subsequent abortions requires a rise in contraceptive prevalence to the level at which all fecund women who do not wish to become pregnant practice 100 percent effective contraception. This "perfect" practice level can be estimated with a straightforward equation from just three factors: the wanted total fertility rate, the average duration of exposed fecund reproductive years, and the average birth interval. In Kazakstan, where the abortion probability is estimated to be 0.81 , a combination of a 9 percentage point rise in prevalence and the elimination of all contraceptive failures sufficed to reduce the TAR from 1.75 to near zero (a small number of abortions would remain among women who change their minds after becoming intentionally pregnant).

The tradeoff between rising contraceptive prevalence and reduced abortion rates that is clearly established by our analysis is not always evident in trends over time. For example, as shown in Figure 1, both contraceptive prevalence and abortion rates in Korea increased between 1960 and 1978. The explanation for this finding is that other determinants of the abortion rate also changed during this period and these changes obscured the tradeoff. Specifically, during the 1960s and 1970s fertility preferences declined, thus leading to a large increase in the demand for the control of fertility. The rise in contraceptive prevalence that occurred in response was apparently not sufficient to meet this demand and thus contributed to a rising abortion rate. In addition, it is likely that the probability of an abortion rose during the 1960s and 1970s in part because of the increasing number of contraceptive failures. Despite these confounding factors there is no doubt that the tradeoff existed during this period, in the sense that a larger increase in contraceptive prevalence would have resulted in lower abortion rates.

The most direct way to reduce abortion rates is to prevent unintended pregnancies by raising the use of effective contraception. Family planning programs, which are now implemented in many developing countries, have contributed to achieving this ob- 
jective by increasing access to contraceptive services through clinics and communitybased distribution systems and by providing education and counseling to remove social and psychological barriers to the adoption of contraception. The reach and quality of these services are still far from adequate in many developing countries, thus making abortion more prevalent than is desirable.

\section{APPENDIX: ESTIMATING MODEL VARIABLES FROM DHS SURVEY DATA}

The total fertility rate and the total abortion rate are calculated for the three-year period before the survey date, using standard procedures (i.e., by summing the corresponding age-specific rates between ages 15 and 49).

WTFR is calculated in the same way as the standard TFR, except that births that occurred after the desired number has been reached are excluded. This is the standard procedure used in all DHS country reports.

$Y_{R}$ equals the sum of the age-specific proportions of women who are fecund and exposed to the risk of pregnancy from ages 15-49. The standard DHS procedure for identifying fecund women is used. Women are considered exposed if they are currently married or in a stable union; are not married but have been sexually active in the last month; or are pregnant, in postpartum amenorrhea, or using contraception.

$u$ is calculated as the sum of age-specific proportions using contraception among fecund exposed women at the time of the survey.

$e$ is estimated as 1 minus the average annual failure rate as calculated by Westoff et al. (1998). ${ }^{14}$

$I_{B}$ is estimated from the following equation, which is obtained by rearranging equation (2):

$$
\mathrm{I}_{\mathrm{B}}=\mathrm{Y}_{\mathrm{R}}(1-e * u) / \mathrm{TFR}-\mathrm{TAR} * \mathrm{I}_{\mathrm{A}} / \mathrm{TFR}
$$

Values for $\mathrm{Y}_{\mathrm{R}}, u, e$, TFR, and TAR are obtained with the above procedures, but $\mathrm{I}_{\mathrm{A}}$ is not readily estimated from survey data. For the purposes of this study, $\mathrm{I}_{\mathrm{A}}$ is assumed to be 14 months, following Bongaarts and Potter (1983). The estimate of $I_{B}$ obtained in this way is therefore an approximation of the true duration, but it is consistent with the measured levels of TFR and TAR and their direct determinants. 
The procedures summarized in this Appendix can be applied to estimate variables and determinants for cohorts as well as for periods, because they are based on the summing of age-specific rates or proportions. Period estimates obtained in this way provide synthetic cohort estimates.

\section{Notes}

The authors gratefully acknowledge comments on earlier drafts of this paper by John Casterline, Germán Rodriguez, Norman Ryder, and four anonymous reviewers. USAID and the Hewlett Foundation provided financial support for this project.

1 TAR is defined as the average number of abortions per woman at the end of her reproductive years, assuming current age-specific abortion rates.

2 Natural fertility rates decline with age because birth intervals lengthen, but also because the proportion of women infecund or unexposed to pregnancy rises with age. The latter factor is typically more important than the former (Bongaarts and Potter 1983).

3 The variable $u$ differs from the conventional prevalence rate in two ways. It is age-standardized (as is proper for a determinant of TAR) and it measures prevalence among fecund exposed women. In contrast, the conventional prevalence rate is affected by the age structure of women of reproductive age and includes exposed women regardless of their fecundity status.

4 Following standard practice, effectiveness, $e$, is defined as the proportional reduction in the monthly probability of conception. The fertility-reducing results of effectiveness so defined are discussed in Bongaarts and Potter (1983). When contraception is not completely effective, unintended pregnancies occur among women who are current users of contraception. The waiting times to these conceptions are embedded in contraceptive use segments and are not readily estimated directly from survey data. The average time women spend in such embedded waiting times to conception is equal to $\mathrm{Y}_{\mathrm{R}} * u *(1-e)$. Segments of effective contraceptive use are not included in $\mathrm{I}_{\mathrm{B}}$ or in the waiting time to conception. 
5 A different rearrangement gives the following model for the total fertility rate: $\mathrm{TFR}=\mathrm{Y}_{\mathrm{R}} *(1-e * u) / \mathrm{I}_{\mathrm{B}}-\mathrm{TAR} * \mathrm{I}_{\mathrm{A}} / \mathrm{I}_{\mathrm{B}}$. This equation can be turned into a multiplicative model for the proximate determinants of fertility similar in structure to that proposed by Bongaarts (1978).

6 With the assumed fixed values of $e, \mathrm{Y}_{\mathrm{R}}, \mathrm{I}_{\mathrm{B}}$, and $\mathrm{I}_{\mathrm{A}}$, equation (2) simplifies to TAR $=16(1-u)-2 *$ TFR.

7 As noted, contraception is assumed to be 100 percent effective. The relationships plotted in Figure 3 are also valid for different fixed values of $e$ if $u * e$ rather than $u$ is plotted along the horizontal axis.

8 Equation (4) simplifies to TAR $=p(20(1-u)-2.5$ ITFR $) /(p * 1.25+(1-p) * 2.5)$.

9 Note that line $\mathrm{AB}$ refers to $\mathrm{TFR}=2$, as was the case in Figure 3.

10 The variable $t$ can be calculated as $t=0.1 * \mathrm{Y}_{\mathrm{R}} * e /\left(\mathrm{I}_{\mathrm{A}}+(1-p) * \mathrm{I}_{\mathrm{B}} / p\right)$. Interestingly, the right-hand side of this equation does not include the TFR, ITFR, or TAR, and $t$ is therefore not affected by these variables. This means that the abortion-reducing effect of a given rise in prevalence is the same regardless of levels of fertility, fertility preferences, or TAR.

11 Some small numbers of abortions of intended pregnancies would occur because of changes in women's circumstances after the conception occurred.

12 The wanted total fertility rate is always slightly lower than the average desired family size because a small proportion of women are unable to have enough births to reach their desired family size.

13 According to equations (2) and (4), TAR is a function of $e * u$. This implies that proportional changes in $e$ and $u$ have equivalent effects on TAR. In the case of Kazakstan, an increase in $e$ from 0.97 to 1 results in a smaller increase in $e^{*} u$ than would an increase in $u$ from 0.65 to 0.74 .

14 As noted by Bongaarts and Rodriguez (1991), this calculation implicitly assumes that the waiting time to conception is one year. This in fact appears to be a good 
approximation for Kazakstan, because the sum of the components of the birth interval then equals 2.6 years, which is virtually the same as that obtained with the above equation for $I_{B}$. The birth interval components are estimated as 12 months for waiting time to conception, two months for time added by miscarriages (Bongaarts and Potter 1983), nine months for a full-term pregnancy, and 8.3 months for postpartum infecundability (National Institute of Nutrition [Kazakstan] and Macro International 1996).

\section{References}

Alan Guttmacher Institute. 1999. Sharing Responsibility: Women, Society and Abortion Worldwide. New York: Alan Guttmacher Institute.

Bongaarts, John. 1978. "A framework for analyzing the proximate determinants of fertility," Population and Development Review 4(1): 105-132.

__ 1997. "Trends in unwanted childbearing in the developing world," Studies in Family Planning 28(4): 267-277.

Bongaarts, John and Griffith Feeney. 1998. "On the quantum and tempo of fertility," Population and Development Review 24(2): 271-291.

Bongaarts, John and Robert G. Potter. 1983. Fertility, Biology, and Behavior: An Analysis of the Proximate Determinants. New York: Academic Press.

Bongaarts, John and Germán Rodriguez. 1991. "A new method for estimating contraceptive failure rates," in Measuring the Dynamics of Contraceptive Use. New York: United Nations, pp. 52-67.

Bumpass, Larry and Charles F. Westoff. 1970. "The 'perfect contraceptive' population," Science 169(951): 1177-1182.

National Institute of Nutrition (Kazakstan) and Macro International. 1996. Kazakstan Demographic and Health Survey, 1995. Calverton, MD: National Institute of Nutrition and Macro International Inc. 
Ross, John, John Stover, and Amy Willard. 1999. Profiles for Family Planning and Reproductive Health Programs: 116 Countries. Glastonbury, CT: Futures Group International.

Tietze, Christopher. 1979. Induced Abortion: 1979, 3rd ed. New York: Population Council. United Nations. 1999. Levels and Trends of Contraceptive Use as Assessed in 1998. New York: United Nations, Department for Economic and Social Affairs, Population Division.

Westoff, Charles F., Almaz T. Sharmanov, Jeremiah Sullivan, and Trevor Croft. 1998. Replacement of Abortion by Contraception in Three Central Asian Republics. Calverton, MD: The Policy Project and Macro International Inc. 


\title{
POLICY RESEARCH DIVISION WORKING PAPERS
}

\author{
Recent Back Issues
}

1998

*106 Sajeda Amin and Gilda Sedgh, "Incentive schemes for school attendance in rural Bangladesh."

107 Martin Brockerhoff and Paul Hewett, "Ethnicity and child mortality in sub-Saharan Africa."

108 Ann E. Biddlecom and Bolaji M. Fapohunda, "Covert contraceptive use: Prevalence, motivations, and consequences."

109 John Bongaarts and Griffith Feeney, "On the quantum and tempo of fertility."

110 Barbara S. Mensch, Daniel Bagah, Wesley H. Clark, and Fred Binka, "The changing social environment for adolescents in the Kassena-Nankana District of northern Ghana: Implications for reproductive behavior."

111 Martin Brockerhoff and Ann Biddlecom, "Migration, sexual behavior, and HIV diffusion in Kenya."

112 Zeba A. Sathar and John B. Casterline, "The onset of fertility transition in Pakistan."

113 Geoffrey McNicoll, "Government and fertility in transitional and posttransitional societies."
114 John Bongaarts, "Fertility and reproductive preferences in post-transitional societies."

115 Fiona Steele, Sajeda Amin, and Ruchira T. Naved, "The impact of an integrated micro-credit program on women's empowerment and fertility behavior in rural Bangladesh."

*116 Cynthia B. Lloyd, Barbara S. Mensch, and Wesley H. Clark, "The effects of primary-school quality on the educational participation and attainment of Kenyan girls and boys."

117 Sajeda Amin and Cynthia B. Lloyd, "Women's lives and rapid fertility decline: Some lessons from Bangladesh and Egypt."

118 James F. Phillips and Mian Bazle Hossain, "The impact of family planning household service delivery on women's status in Bangladesh."

119 Mark R. Montgomery and John B. Casterline, "Social networks and the diffusion of fertility control."

* No longer available 
*120 John Bongaarts, "The fertility impact of changes in the timing of childbearing in the developing world."

*121 James F. Phillips, Wendy L. Greene, and Elizabeth F. Jackson, "Lessons from community-based distribution of family planning in Africa."

122 Mark R. Montgomery, "Mortality decline and the demographic response: Toward a new agenda."

123 Mark R. Montgomery, Mary ArendsKuenning, and Cem Mete, "The quantity-quality transition in Asia."

124 Barbara S. Mensch, Wesley H. Clark, Cynthia B. Lloyd, and Annabel S. Erulkar, "Premarital sex and school dropout in Kenya: Can schools make a difference?"

125 John Bongaarts and Rodolfo A. Bulatao, "Completing the demographic transition."

126 Geoffrey McNicoll, "Population weights in the international order."

127 Cynthia B. Lloyd, Carol E. Kaufman, and Paul Hewett, "The spread of pri- mary schooling in sub-Saharan Africa: Implications for fertility change."

128 John B. Casterline, “The onset and pace of fertility transition: National patterns in the second half of the twentieth century."

129 Mark R. Montgomery, Michele Gragnolati, Kathleen Burke, and Edmundo Paredes, "Measuring living standards with proxy variables."

130 Bamikale Feyisetan and John B. Casterline, "Fertility preferences and contraceptive change in developing countries."

131 Martin Brockerhoff, "Urban growth in developing countries: A review of projections and predictions."

132 Omaima El-Gibaly, Barbara Ibrahim, Barbara S. Mensch, and Wesley H. Clark, "The decline of female circumcision in Egypt: Evidence and interpretation."
133 Mary Arends-Kuenning and Sajeda Amin, "The effects of schooling incentive programs on household resource allocation in Bangladesh."
134 John Bongaarts and Charles F. Westoff, "The potential role of contraception in reducing abortion."

* No longer available 